\title{
Prerrogativas del derecho a ser persona
}

\section{RESUMEN}

Esther Fragoso Fernández *

La Declaración de los Derechos Humanos se refiere a las condiciones materiales y espirituales inherentes al ser humano que se fundamentan en su dignidad y en el valor de sus cualidades intrínsecas, por lo que reconoce a la mujer y al hombre en su humanidad, es decir, como seres en sí y que están orientados a su plena realización como personas y no como medios para otros fines.

Cuando uno se refiere a la persona, en realidad se hablará del ser humano, entonces la pregunta correcta es ¿quién es el ser humano?, es decir, ¿qué es un ser?, y ¿qué lo hace humano?; si se analiza desde la perspectiva filosófica, la respuesta no será tan simple y ni siquiera unívoca. A lo largo del artículo se tratará de escudriñar ¿quién es una persona?, o dicho de otro modo, ¿qué hace a la persona ser persona?; no se hablará de la persona como concepto, sino de la persona existente, real y concreta, con todo lo que

ello significa; de las diferentes dimensiones que la constituyen y de la unidad indisoluble de los atributos que hacen ser a cada uno, persona única.

\section{ABSTRACT}

The Human Rights Declaration refers to the material and spiritual conditions inherent to the human being, which are based in his dignity and in the value of his intrinsic qualities, for which woman and man are recognized in their humanity, that is, as beings themselves who are oriented to their complete fulfilment as persons and not as means to other aims.

When we refer to a person, we are actually talking about a human being. So the correct question would be: what is a human being? Meaning what a being is and what makes it human? From a philosophical point of view, the answer wouldn't be so simple, or even univocal. Throughout the article we will try to scan what is a person or, in other words, what makes a person be a person; we will not refer to a person as an abstract concept, but to the existing person, real and concrete, with all what it means; to the various dimensions which constitute it and to the insoluble union of the attributes which makes each one of us, a unique being.

\footnotetext{
* Maestra en Educación Familiar por la Universidad Panamericana, Licenciada en Filosofía por la Universidad Nacional Autónoma de México. Docente-Investigadora de la Universidad La Salle Pachuca. efragoso@lasallep.edu.mx
} 


\section{El hablar de derecho remite a dos significados.}

Hablar de derechos alude de una forma inmediata a la facultad o poder de actuar, oportunidad de obrar de determinada manera o exigir una conducta a alguien (Océano, 1987) y son derechos humanos porque los hombres y mujeres son los únicos destinatarios de su cumplimiento.

Desde el punto de vista subjetivo el derecho es la facultad, poder o potestad individual de hacer, elegir o abstenerse; en sentido amplio se entiende como el poder de permitir o prohibir a los demás aquello que busca su propio bien o le perjudica. También es entendido como la facultad o poder de hacer, de tener y de exigir por parte de una persona sobre una cosa.

Desde el punto vista objetivo es el orden normativo e institucional de la conducta humana en sociedad, inspirado en postulados de justicia.

El sentido normativo, los derechos son el conjunto de normas que regulan determinada sociedad incluyen las leyes, reglamentos y demás resoluciones, de carácter permanente y obligatorio, creadas por el Estado para la conservación del orden social.

El sentido moral remite al cumplimiento de los derechos:

La estructura moral cualifica a las personas para que se vean inclinadas y dispuestas a respetarlos y defenderlos. Podemos ver esa estructura como constituida por ciertas virtudes éticas y empotradas en la libertad del hombre, que se va educando y formando como la realización del bien, sobre todo del bien de los demás, del bien de todos, del bien común (Beuchot, 2000: 51).

El bien común es indispensable para la construcción de la sociedad, representa el espacio donde la persona encuentra su realización; porque es en la persona donde se reúnen el bien individual y el bien común.

El análisis de los diferentes conceptos de derechos humanos es planteado desde corrientes políticas no como ideales o buenos deseos a alcanzar algún día por la humanidad, sino que exigen la profundización teórica, lo que permitirá validar su defensa en la praxis, porque, si se parte de la situación concreta que impera en varios sectores de la realidad:

Se tiene de ellos dos caras: por una parte el hecho de que con mucha facilidad e impunidad son violentados en muchas personas (arrestos injustificados, torturas, amenazas,...) y por otra parte, la otra cara de la situación, siempre se ha dado la corriente histórica de profunda defensa tanto en la parte práctica como en la teórica (Beuchot, 2000:60).

Es urgente pasar del discurso a la acción garantizando su aplicación.

Este estudio parte del fundamento de los derechos humanos en la dignidad 
de la persona, es decir, todo hombre, por ser humano, sin importar su edad, religión, sexo o condición social, goza de ellos. Los derechos humanos son así entendidos como facultades prerrogativas y libertades esenciales que tiene toda persona por el simple hecho de serlo, nacen de la propia naturaleza del ser humano, sin ellos no podría vivir como tal, es decir, como persona. La propuesta de este artículo es reflexionar a qué nos conduce el derecho de ser persona.

\section{¿Qué es la persona?}

Desde el punto de vista etimológico, Gómez de Silva (2001:538) la palabra persona deriva del latín persona: personaje de teatro, papel del actor y del griego prosopon: cara, máscara. El primer acercamiento a lo que la palabra persona significa es que se trata de algo que cubre lo que auténticamente somos.

- Se es máscara porque a veces, hipócritamente sólo se actúa lo que los otros esperan de uno para ser aceptados en el grupo social: "el gracioso", "el intelectual", "el comprensivo".

- Se es la máscara del actor porque a lo largo de la propia biografía se tienen que jugar diferentes papeles en este teatro que es la vida, entonces se es "la hija", "la profesionista", "la madre", "la ciudadana".

- Cuando uno se pregunta ¿quién soy? en este momento sólo se puede responder que se es una máscara, pero una máscara que ha nacido con la tarea de develar su real identidad, de "descubrir" su verdad. La tarea de la vida es descubrir, o sea quitar la cubierta de esta máscara de Esther y convertir en acto toda la potencialidad que está en lo más íntimo de mi ser, planificarse como lo que verdaderamente se es; dicho a la manera de Víktor Frankl (2002:104): "El imperativo de Píndaro acerca de la persona tiene que acabar en convertirse en lo que realmente es, en otras palabras, el hombre debe actualizar sus potencialidades."

Desde el punto de las ciencias naturales, el hombre es un ser biológico, cuyo cuerpo posee características específicas. La genética afirma que el hombre nace con potencialidades propias de la especie y otras más, propias de su persona. Lo singular del hombre -desde el punto de vista biológico- es que es un animal con un cerebro único, "su nicho cognitivo" cuya superioridad se evidencia por su rendimiento intelectual.

Según Ganten D. Deichmann T. y Spahl T. (2004:431-432) la percepción humana —desde el punto de vista- físico se da en fases: con los ojos, los oídos, la nariz, la lengua y la piel se reciben los estímulos físicos del entorno que se traduce en impulsos nerviosos eléctricos y se envían al cerebro; ahí se crean a partir de ellos, los estados de conciencia. Así, la idea que cada quien tiene del mundo exterior, se basa en la interpretación que cada uno 
formula en este proceso.

Desde el punto de vista filosófico existen diversas posturas acerca de lo que es la persona. El materialismo sostiene que el primer requerimiento del hombre es sobrevivir, por lo que la madre le brinda alimento y cobijo; de aquí se podría concluir que la actividad humana originaria es la económica o sea, procurarse bienes materiales: vivienda, alimento y vestido. Pero no se puede quedar uno con esta perspectiva exclusivamente, si se analiza esto más allá, tener vivienda es construir la percepción primitiva de la existencia humana, Arregui y Choza (1995: 454) porque es encontrarse con la verdad del hombre y del cosmos; tener vivienda es tener mi mundo, concebir qué es lo que me rodea y la ubicación que tengo dentro de ello.

De la misma manera, tener vestido, descubre al ser humano mucho más de lo que lo cubre, el vestido manifiesta quién es ese hombre: a qué grupo pertenece, qué papel juega en él; el vestido da identidad al individuo, lo identifica en sus gustos, quizá en la generación a la que pertenece, la clase social determinada y el vestido, ampliándolo a todo el arreglo personal, expresa lo que cada hombre va inventando de sí mismo, muestra las reglas del juego de ese hombre en específico, dice su unicidad, parte de su irrepetibilidad.

De aquí que la primordial necesidad del ser humano sea la apertura a lo que le rodea, es el logos que lo distingue como lo que es, un hombre con la necesidad inexorable de comprender, de interpretar lo circundante, de explicar la realidad, no cualquier realidad, sino su realidad — de hecho la única que le es posible entender-; lo cual se traduce en la imperiosa necesidad de comprenderse a sí mismo, es decir, entender ¿quién es él?

Debe considerarse también que la persona es "persona en la vida", una vida que un día percibió que tenía, que se le dió como un regalo. $Y$ ¿qué se hace con un regalo?, se abre, se aprecia y se disfruta. La vida se inicia al abrirse a los demás, al vincularse con los otros, la propia naturaleza está hecha para donarse, para darse a los demás: ¿dar qué?, "dar-se", dar lo que se es; uno alcanzan la plenitud cuando se es "más" uno mismo, es decir, cuando se es capaz de dar esto que se ha construido de sí a los otros: el niño da una sonrisa a su madre, el joven da su atención al amigo, el padre da su experiencia al hijo. Constantemente entregamos las propias ideas, las carencias, el amor, lo más íntimo de sí.

Otro acercamiento es considerar que la persona es el yo. $Y$ ¿quién es yo? Yo es el sujeto, es quien vive, la vida transcurre y el yo permanece. La vida son los hechos que suceden y el 'yo' es el sujeto al que le suceden. La biografía de la vida es la biografía del 'yo', pero de un 'yo' que no se identifica con su biografía, sino que es su propietario. El 'yo' es una sustancia 
-en el sentido aristotélico - al que le hieren, a veces hasta la raíz, sus accidentes. Así, ese 'yo' está modificado por sus actos pero, se distingue de ellos, no es un sustrato inalterable pero tampoco se reduce a la unidad de sus actos. ¿Qué le resta a ese yo cuando se han eliminado todos sus actos? La vida es un conjunto de acontecimientos en el mundo, pero el yo que la vive no es un hecho más que suceda en el mundo, entonces como afirma Arreguí y Choza (1995:462) el yo no es mundano. El hombre es siempre el mismo, pero no es siempre lo mismo.

Se es persona cuando se sabe que se es persona, esto es, cuando uno se hace consciente de ser, palpa su existencia y se hace consciente de que su existir es como persona. Es el momento de encontrarse con su persona, de no evadirla, escapando al pasado ni al futuro, sino de estar en presencia aquí, en la confrontación con todo lo que se es. En ese momento no sólo se está presente ante uno mismo, sino también ante el otro, con los propios pensamientos, actos, con el propio ser ante el otro.

De la conocida definición de Aristóteles de hombre como un ser animal de naturaleza racional (zóon lógon échon, "animal que posee razón o logos») se sigue que en este sentido la naturaleza del hombre es fundamentalmente espiritual, es el logos o naturaleza racional que lo lleva a la comprensión del mundo y de sí mismo.

El alma, desde el punto de vista biológico es lo que constituye a un organismo vivo, diferenciándolo de los seres inertes, y como tal, no es exclusiva del ser humano. La noción de alma fue pensada así por Aristóteles para explicar a los seres orgánicos vivos, pero no es una noción que se oponga a la de cuerpo, porque un organismo vivo es un cuerpo animado, no es un cuerpo más un alma, sino un cierto tipo de cuerpo; el alma es "la causa y el primer principio del cuerpo vivo" afirma Aristóteles (1964:405). El alma es la forma del cuerpo, es aquello por lo que el hombre vive, siente, se mueve y entiende, es el principio de las operaciones del cuerpo. El alma no es una sustancia que se superponga o añada al cuerpo, ni tampoco es un elemento más de él, sino es el acto primero, es la esencia del cuerpo que posee la vida en potencia.

El cuerpo está vivo no por ser cuerpo, ya que hay cuerpos inertes, sino porque es un tipo de cuerpo determinado, la forma es este principio de determinación, aquello por lo que un ser es lo que es, el alma es el principio de unificación del ser vivo, su forma sustancial. Alma y cuerpo no están al mismo nivel, no son dos paralelos de realidad, el alma es el acto del cuerpo que posee la vida en potencia; el alma es la realidad de vida cuya posibilidad es el cuerpo.

Se puede reflexionar que cuanto más el hombre está despierto a su 
espiritualidad es más responsable, es decir, responde, actúa de acuerdo a lo que se espera de su naturaleza más íntima. Ser un ser espiritual, es ser un humano pleno. En palabras de Víktor Frankl (2002:41) "Es lo espiritual lo que hay de humano en el hombre."

El camino que hemos de recorrer no es la inteligencia - ya que lo que permite ver a la vista, no es el objeto visto- en el mismo sentido, el espíritu y la conciencia son consecuencia de algo, sería absurdo decir que la conciencia se hace consciente de sí misma, porque entonces, habría por un lado, quién es consciente y por otro, de lo que es consciente; no serían uno sino dos. No es buscar que la conciencia se conozca, sino es buscar, que al ser consciente de lo que eres, realmente lo seas, es decir, te conviertas en ello.

\section{CONCLUSIÓN}

En el orden de ser, la persona es la sustancia, lo esencial o primario; en el orden del bien, la acción del hombre es lo definitivo y por lo tanto, lo que le hace bueno, pero a su vez esta acción en el orden del ser es sólo un accidente y no depende, como tal, de la sustancia. Tomando en cuenta la realidad precaria del ser humano y su posibilidad de actuar libremente, debe asirse de un esfuerzo continuo que lo lleve a ser mejor persona cada vez; momento en el cual alcanzará la dignidad moral -de sus actos- a la dignidad ontológica -de su ser-.

El ser humano en lo más íntimo de sí, se torna digno -si es que se pudiera afirmar "más hombre"- en cuanto va mejorando en el cumplimiento de su deber más radical: convertir en actualidad la perfección contenida en su ser desde el momento del existir. Dicho a la manera de Melendo (1999: 127) "El hombre es el arquitecto de su propio destino".

Es así que el derecho a ser persona, nos lleva en sintetizar, a tener que contestar ¿qué es la persona?, es decir ¿quién es ese ser al que tengo derecho a ser?, a lo que se puede responder, la persona es un hombre o una mujer, pero no cualquier hombre o mujer, sino, un ser espiritual expresado en un cuerpo material, un ser que se posee a sí mismo, consciente de sí y, por lo tanto, de sus actos. Está dotado de una intimidad, desde la cual, le da sentido a su existencia. Es un ser que se entrega, y en esa entrega, es más él mismo: por lo tanto, no sólo comunica sino se comunica a sí mismo, es para el otro; y al darse en el otro se complementa, es decir, se plenifica y se vuelve uno -con el otro.

Más que descubrir qué es ser persona se han abierto brechas a la reflexión, lo que lleva a concluir que saber quiénes somos es una tarea constante que se tiene que ir redescubriendo cada día hasta llegar a serlo y fundirse en ello eternamente 


\section{FUENTES DE CONSULTA}

ARISTÓTELES (1964). Obras. Madrid, España: Aguilar. Lógica, Metafísica, Política, Ética a Nicómaco, Sobre el Alma.

ARREGUI Y CHOZA, Vicente. (1995). La filosofía del hombre. Una antropología de la intimidad. España: Rialp.

BEUCHOT, Puente Mauricio. (2000). Los derechos y su fundamentación filosófica, México: Universidad Iberoamericana.

FRANKL Victor. (2002). La presencia Ignorada de Dios, Barcelona, España: Herder.

- (2001). El hombre en busca de sentido. España, Herder.

GANTEN D., Deichmann T. y Spahl T. (2004) Vida, Naturaleza y Ciencia, Todo lo que hay que saber. México: Taurus.

GÓMEZ DE SILVA, Guido. (2001). Diccionario Etimológico de la lengua española México, Fondo de Cultura Económica.

MELENDO, Tomás. (1999). Las dimensiones de la persona. Madrid, España:

Ediciones Palabra

OCÉANO Grupo Editorial (1987) Diccionario. Barcelona: Ediciones Océano S.A. 